\title{
Developing Culturally Specific Tools for the Evaluation of Good Governance in Diverse National Contexts: A Case Study of the National Olympic Committee of the Islamic Republic of Iran.
}

\author{
Mehdi Ghadami and lan Henry
}

\begin{abstract}
One of the key features of the Olympic movement is its universalistic appeal, particularly in the sense that it has sought to establish itself as a platform for universal interaction and promotion of universal values. In this paper we consider the nature, feasibility, and implications of the IOC's promotion of its universalist position in terms of the ethical standards it promotes in relation to universal principles of good governance.
\end{abstract}

A major problem in this respect is the culturally diverse set of constituencies which are incorporated within the Olympic movement, such that the imposition of 'one size fits all' policies may be impractical and in many instances undesirable. The authors of this paper therefore argue that although universal agreement is often impractical, general agreement may often be established. The paper therefore presents an approach to balancing centrally promoted principles of good governance with local preferences in terms of the weighting to be given to particular values within the operationalisation of good governance. This approach based on the Analytic Hierarchy Process technique, developed by Thomas Saaty and widely employed in decision-making with regards to evaluating and weighting alternatives, is introduced here in the context of the evaluation of National Sport Federations in Iran. The paper highlights ways in which this technique allows for the expression of local priorities within the general framework of good governance principles in ways which satisfied both global and local priorities. In effect it is a practical example of what Robertson has termed glocalisation.

The paper concludes by applying this framework to an evaluation of the National Federation for Football in Iran as an example of how this technique will be used for the purposes of ranking National Federations in terms of performance with respect to elements of good governance which will inform both self-assessment by the NF, and the decision-making process for allocation of funds by government to national federations in Iran in the future.

\section{Introduction}

One of the key features, indeed attractions, of the Olympic movement and the Olympic Games (at least in its Summer Games form) is its 'universalistic' appeal. The IOC has for example more member nations (205) than the United Nations (192), and although historically born out of a body dominated by Western European, male, aristocratic origins (and despite the fact that its membership, and the sporting forms it incorporates in the Games still reflect these origins [1]) it has subsequently sought to establish itself as a platform for universal interaction and the promotion of universal values. Indeed if one reads the Olympic Charter [2] it seems clear that the Olympic movement presents as its primary goals, not sporting, but ethical aspirations and that this position of principle has implications for the ways in which operational decisions about management of Olympic sport may be taken.

In this paper we consider the nature, feasibility, and implications of the IOC's promotion of its Universalist position in terms of the ethical standards it promotes in relation to 'universal' principles of good governance. We will argue that there is a tension between universal prescription and democratic rights of self-governance, and will review one attempt to deal with this tension at operational level in the Olympic system of Iran. 


\section{Olympic Values, Discourse Ethics and the Development of General rather than Universal Ethical Consensus}

The IOC's position is in theory tied to the expression of universalism, but in practice it has to be pragmatic in incorporating cultural variety even in some fairly central practices [3]. If for example we consider the Olympic Charter requirement that governmental or political influence should be absent from policy matters relating to National Olympic Committees such as influencing the election or appointment of NOC members or executives [2], a fairly obvious conclusion is that there are varying degrees of governmental intervention in NOCs and/or National Federations across the world. It is clear that the institutional separation of sport from politics is not universally achieved/respected. In some instances the IOC has felt able, and deemed it necessary, to intervene to ensure state influence is diminished or kept in check. In 2012 and 2013, the IOC for example both wrote to, and met with, the Iranian government on a number of occasions on this issue, and in 2013 and 2014 dealt with cases similar cases in India [4], Ecuador and Pakistan [5] and Egypt and Sri Lanka [6]. These actions on the part of the IOC have however been subject to criticism from some quarters as inappropriate intrusion into the domestic politics of nation states. Carpenter, a consultant for the LawInSport organisation, has argued that:

Despite being a purely private body, it appears that the $I O C$ is acting as a supranational body dictating to NOCs, and therefore national governments (directly or indirectly), how sport should be run in their respective country (sic). This is despite the fact that many of the changes the IOC is insisting upon to sporting legislation, either sports regulations or national laws, are in the main progressive, as the Fundamental Principles of Olympism are all about a positive and inclusive attitude to sport. Yet one cannot help feel uncomfortable that the IOC feels it appropriate to dictate to national governments the content of such legislation and timescales within which such amendments must be made. After all, it is not national governments who have signed up to the $\mathrm{OC}$ - rather it is the NOCs who have signed up to this private contract with the IOC. [7: p. 1].

However, although the cases we have cited represent examples of IOC intervention, in cases such as the Russian Federation, China, or Vietnam, despite prima facie evidence of governmental involvement / intervention / interference (the term employed here constitutes a discursive and pejorative construction of the nature of the activity involved), the IOC has not intervened to require the withdrawal of state intervention.

Notwithstanding these difficulties, the general approach expressed within the Olympic Charter is, as we have noted, one of universal values, rules, or requirements etc. We have contrasted this universalistic philosophy elsewhere [3] with claims of cultural specificity and incompatibility as represented in the 'Clash of Civilisations' thesis of Samuel Huntington [8]. Huntington's approach was arguably the cultural analysis most influential in informing the neo-conservative politics of international relations among American commentators at the turn of the century $[9,10]$. The Clash of Civilisations thesis characterised the post Cold War era as a shift from a bi-polar political context to a multi-polar scenario in which the global political system was made up of nine civilisation groups whose value systems were fundamentally incompatible. Thus Huntington's thesis rejected the possibility of universal consensus on fundamental value questions.

It has been argued that the 'Clash of Civilisations' view of international relations is both dangerous and mistaken. It is dangerous because a consequence of this perspective is that since there is no means of coming to a consensus or compromise on basic value disagreements in particular between the West and Islam, that for the West to prevail in political disputes based on value positions ultimately force would be necessary. As such it is the very antithesis of a discourse ethics scenario as promoted by Habermas [11] ${ }^{1}$.

\footnotetext{
${ }^{1}$ In response to Huntington's thesis the Iranian President Mohammad Khatami introduced a proposal for Dialogue among Citizens, with the United Nations subsequently declaring 2001 the Year of Dialogue Among Citizens in response to his proposal.
} 
Habermas argues that universal principles across cultural groups can be established. Indeed he bases his argument around a principle of universalization which is the condition every valid norm has to fulfill. A necessary condition of communication, he argues, is mutual understanding, or understanding in common. In other words we have to agree on the common meaning of terms sentences, descriptions etc, including agreeing on the meaning of moral norms. Discourse is required as the medium of discussion of the validity of norms. And at the heart of Habermas's argument is discourse principle that

(D) Only those norms can claim to be valid that meet (or could meet) with the approval of all affected in their capacity as participants in a practical discourse. (Habermas, 1990:65)

Thus for Habermas, intersubjective understanding and approval of moral principles (achieved through discourse) are required to develop universal moral principles.

However, our position departs from that of Habermas's normative ethics of how moral positions ought to be decided, to that of an emphasis on empirical ethics, establishing how moral positions are actually arrived at, and their general (rather than universal) acceptance [3]. Through discourse about ethics one is much more likely to arrive at general norms (norms which can be generalised across different groups when the premises of what constitute public morality are formally negotiated and agreed) than at universal principles which will be agreed and accepted by all. This approach suggests that while one can rarely publicly identify moral judgements which will be true in all places, at all times, for all people, this does not mean that one has to accept that anything goes, and that no general moral claims can be made. Nevertheless such general claims still have to be founded on negotiated principles, and this is the nature of discourse ethics.

By contrast under a Huntington approach, if the West wishes to ensure that its own values will prevail, discourse is ultimately futile and the use of military force will be the only option. This for some was a premise or rationale for US-led western involvement in Iraq and Afghanistan. The 'Clash of Civilisations' philosophy is thus regarded by some commentators as dangerous, but it is also viewed as erroneous. It promotes a notion of civilisations being 'hermeneutically sealed', developing a separation or segregation from one another in terms of the sharing of important values. This characterisation of cultures is not one which squares with our experience of the globalised and culturally diverse world. In fact there is often far greater consensus across cultural groups than there is within them, as Tibi [12] illustrates in relation to Muslim and non-Muslim societies, and as we have argued elsewhere (with reference to Karam's typology [13]) in relation to feminism in Muslim and non-Muslim majority countries [3].

In our increasingly globalised environment, interaction between cultures has inevitably intensified. The UN encompasses debate and compromise on military activities, the WTO on trade and economic activities, while the Olympic movement constitutes engagement in the cultural domain. Those forms of engagement, potentially at least, constitute venues for what Habermas advocates in terms of discourse ethics.

Given our view of the establishing of general moral principles through discourse we promote the notion of general (rather than universal) principles of good governance being a more adequate description of the process being undertaken, with a general agreement about the principles to be reflected in good governance but with an anticipated degree of cultural specificity in the interpretation and implementation of those principles. This contrasts with the use of the term 'universal' in the literature (e.g. the IOC's Basic Universal Principles of Good Governance of the Olympic and Sport Movement). The distinction between the assumptions of the Clash of Civilisations approach of Huntington (Figure 1), the Discourse ethics approach of Habermas (Figure 2) and our own approach (Figure 3 ) is highlighted diagrammatically in simplified form in the Figures below. 
Insert Figures $1-\mathbf{3}$ about here

\section{The Universal Principles of Good Governance of Olympic Organisations}

The IOC's focus on the identification of, and promotion of adherence to, principles of good governance has intensified since its own governance crisis in the wake of the Salt Lake City corruption scandal [14]. Its own 2000 Commission Report [15] introduced 50 measures, many of which constituted measures of good governance, though it has been argued implementation of these measures in real terms has been limited [14]. At its Congress in 2009 Thomas Bach (Vice President of the IOC at that time) presented a view of the application of principles of good governance [17] which was to become the basis for The Basic Universal Principles of Good Governance which were approved by the Congress. This had grown out of the IOC's seminar the previous year which had sought to operationalise these principles [see 17].

The IOC's attempt to define and operationalize principles of good governance however was by no means an isolated attempt to do so. In their review of basic governance indicators for international sport, Chappelet and Mrkonjic [18] provide perhaps the most comprehensive available review of attempts by organisations (international governmental organisations, international and European sports associations, national sports associations and agencies, international non-governmental organisations, and transnational organisations) and by academic authors [19-26] to define and measure aspects of good governance in sport.

\section{The Problem}

The research problem therefore which this paper addresses is premised on two conditions. If universal prescriptions of sport governance are not always appropriate [for the reasons given above in the quotation cited by 8 , in which the need to respect local difference and autonomy is identified]; and if Olympic sport is an arena for the development of inter-cultural dialogue which may result in general if not universal consensus; then how can an approach to sporting governance be adopted which reflects this general consensus, while also allowing the expression or realisation of local political and cultural priorities, reflecting also the general consensus around the need for good governance in sport? We address this general problematic in the context of an exercise being undertaken by the NOC of the Islamic Republic of Iran which seeks to provide an operational measure of good governance against which to evaluate and compare the performance of its own National Sport Federations for both self assessment purposes and in order to use good governance as a criterion for making annual funding decisions.

\section{Methodology - Part 1: the Approach to Operationalising Measures of Good Governance in Iranian National Sport Federations.}

Operationalising the measures of good governance to be applied in evaluation of the national federations in Iran was completed in four stages over the period December to March 2012-13, with a fifth stage - the piloting of application of the operational measures in an evaluation of the governance performance of selected National Federations taking place in April and May 2013 (see Table 1 for an 
outline of tasks required). At the time of writing only the results of the evaluation for the first association to be evaluated, namely the Iranian Football Association, were available.

The first stage of the preliminary process was to review the literature on the governance of sport to identify the different approaches to defining the criteria of good governance in sporting organisations in the literature, to consider their respective merits, and subsequently to select or to construct a set of criteria for the purposes of evaluation of governance practices in the Iranian National Federations. The first named author undertook a review of the literature, summarising this for the purposes of discussion in interviews with the main actors in the Iranian sports system. The discussions with interviewees largely reduced to the respective merits of two sets of criteria, namely those of the Chappelet and Mrkonjic [18] which seeks to draw more directly on the IOC's own criteria of good governance; [18] and which focuses on the following: organisational transparency, reporting transparency, stakeholder representation, democratic process, control mechanisms, sport integrity, and solidarity; and Henry and Lee [27] which identifies seven key factors namely, accountability, transparency, democracy, effectiveness, efficiency, responsibility, and equity. Chappelet and Mrkonjic reject certain elements of the Henry and Lee typology (specifically effectiveness and efficiency), because they argue that these relate to management rather than governance. However we would argue that responsibility for effective and efficient management processes is also a governance issue, and this was a major factor in the decision to employ Henry and Lee's typology supported by the majority of the interviewees.

The second stage in the process also undertaken via the interview group which took part in Task 1, was to select seven sub-elements for each of the seven criteria identified in the Henry and Lee study. The selection of seven sub-elements, as operational measures for each of the seven criteria of good governance reflects the authors' intention to ensure that each criterion of good governance should be evaluated across a relatively broad range of measures. The same senior political and managerial figures as those involved in Task 1 were engaged in the process of identifying the sub-elements for each principal criterion of good governance. Table 5 below provides an example of the sub-elements for one of the criteria of good governance identified by Henry and Lee.

The third stage of the process involved weighting the seven principal criteria of good governance. This was undertaken with the NOC Management and Planning Commission which acted as an expert focus group. The technique employed to derive weighted comparisons of the seven principal criteria was that of the Analytic Hierarchy Process (AHP). AHP is an approach developed by Thomas Saaty [28] and widely employed in decision making with regard to the evaluating and ranking of alternatives. It has been used in a broad range of contexts from weapons purchasing to evaluating the quality of research [29]. The approach uses the judgement of decision-makers to decompose problems into hierarchies. The hierarchy is used to derive ratio scaled measures for decision alternatives. One of its attractive properties is the ability to accommodate qualitative or quantitative data in generating hierarchies.

\section{Insert Table 1 about here}

The AHP approach involves five steps.

a. It begins with the definition of a problem - the goal of this aspect of the analysis. In the current case the problem relates to which national federations have the best overall performance in terms of governance.

b. AHP then requires that the factors which influence that goal be defined. Again in the current case the seven elements of good governance identified by Henry and Lee represent the list of factors pertaining to this task.

c. The third step involves paired comparison. In the current case this is a set of paired comparisons of the importance of criteria identified to the goal of good governance. The comparisons are conducted for every possible pairing of the seven criteria of good governance (21 pairs in all) and recorded for each respondent on a single table. Comparisons 
are scored in the manner outlined in Table 2. Thus for example when comparing the relative importance of Transparency and Equity to Good Governance, values may vary from Transparency being regarded as extremely important (value of 9) compared to Equity (which is given the value of the reciprocal of 9, i.e. $1 / 9$ or 0.111 ). If however Effectiveness and Efficiency are taken to be of equal value each would be accorded a score of value 1.

In the case of this study eight members of the Expert / Focus Group provided a set of comparisons for the 21 pairings of the seven factors. Table 3 provides an illustrative sample of output for one of the members of this Expert / Focus group.

d. In the fourth step the level of logical consistency of each of the sets of comparisons made is assessed. The notion of consistency here is that if in paired comparisons the claims is made that $X>Y$, and $Y>Z$, then to be consistent the comparison of $X$ and $Z$ would be that $X>Z$ rather than the converse. Saaty as part of the AHP approach allows for tolerance of a certain level of inconsistency given the nature of human judgement. He uses the calculation of a Consistency Ratio which represents a ratio of the level of consistency actually shown to that which might be shown in a random set of values for paired comparisons. Where the Consistency Ratio is less than 0.1 the values from the tables of paired comparisons are deemed acceptable. ${ }^{2}$ However where a table of comparisons has a Consistency Ratio of $>=0.1$ then these tables are rejected as inconsistent.

Paired comparisons for two of the eight members of the Expert/Focus group were excluded from the analysis because the Consistency Ratio for the table of paired comparisons they provided exceeded the critical value of 0.1 .

e. The fifth step in the process involved combining the six remaining sets of paired comparisons and calculating the Priority Eigenvector (or normalised Eigenvector) value for each of the elements. 'Expert Choice' software was employed for the calculation of the logical consistency of the paired comparisons (Comparison Ratio) and of the relative weighting (Priority Eigenvectors) of each of the elements of good governance [31]. Table 4 provides the relative weightings calculated on the basis of the Expert / Focus Group's judgement.

\section{Insert Tables 2- 4 about here}

The fourth stage of the overall process involved assessing the level of importance of each of the subelements of the criteria of good governance. This was undertaken through a questionnaire survey of the members of the General Assembly of the NOC (piloted first with members of the Canoe Federation) which asked respondents to evaluate the importance of each sub-element to the meeting of the criterion of good governance, scaling their response on a five point scale from 1 (unimportant) to 5 (very important). In Table 5, the column headed 'Importance Factor' provides an example of the weighting of the seven sub-elements for one of the main criteria of good governance, namely 'transparency'.

Insert table 5 about here

\section{Methodology - Part Two: Application of the Method to Assess the Quality of Governance in Iranian National Governing Bodies; the Case of the Iranian Football Federation.}

\footnotetext{
${ }^{2}$ For an account of calculation of the normalised eigen vector from a set of paired comparisons and the calculation of Consistency Index, Random Index and Consistency Ratios see for example Tekonomo 31. Teknomo, K. Analytic Hierarchy Process (AHP) Tutorial, Available from http://people.revoledu.com/kardi/tutorial/AHP/. 2006 [cited 201422 April]..
} 
Having established the relative weights to be given to the seven main criteria of good governance and the relative importance accorded to the sub-criteria within each of these main criteria, the tools were in place to undertake an evaluation of the governance practices and performance of national sport federations in Iran. The process of evaluating the performance of national federations is undertaken by the NOC Monitoring Center. Thus, the experts of the Center, employing the tools developed as described in the above section applied these to a pilot evaluation of the performance of a major national federation, the Iranian Football Federation, in respect of each sub-criterion under each of the main criteria of good governance. The federation's performance for each of these sub-criteria was evaluated on a score from 0-4, with zero representing 'no evidence of meeting this sub-criterion, through evidence of poor performance (1), moderate performance (2), good performance (3), and very good performance (4). The score agreed by the Committee is given in the column headed 'Raw Score' in Table 5.

The product of the raw Score and the Importance factor provides a 'Final Score' for each subcriterion, with the value for the main criterion as a whole being calculated by the formula:

\section{$\sum$ (FS) $\times 100$}

$4 \sum$ (IF)

In the case of the data for Transparency reported in Table 5 this yields a total points score for the main criterion of Efficiency of $61 \%$.

In Table 6 the values in the column 'Total points Score for Main Criterion of Good Governance (\%)' are multiplied by the values in the column 'Weight Factor (WF) derived from AHP analysis (1-100)' to provide a final score for each criterion which are summed and divided by 100 to render an overall governance score for the football federation.

\section{Insert Table 6 about here}

\section{Interpretation and Presentation of the Governance Scores of National Sport Federations}

At the end, the final score of each criterion and overall governance of federation are categorized through a conversion table (Table 7). The score achieved for each main criterion shows the present status of federation's governance in that field and can be used by the NOC as the final evaluation result. If the score of a criterion is under 20, the federation's governance status in that specific criterion will not be acceptable. If the score acquired for a criterion is 91-100, this part of the federation's governance can be considered as an appropriate pattern for the other National Federations.

\section{Insert Table 7 about here}

The final scores obtained for each criterion in step 1 can be summarized and presented as the final outcome of the evaluation through a spider chart (Figure 1) showing each federation's achievement as a percentage of the maximum possible score, for each of the seven main criteria.

\section{Insert Figure 4 about here}

\section{Conclusions}

In this paper we have sought to identify ways in which the claims for the development of universal agreement on matters such as good governance in the context of the Olympic movement are rather more an aspiration than a practical outcome. For the most part agreements on cultural or ethical norms in sport, or for that matter, in trade, international relations, or social justice and human rights, are rarely universal though in many instances they are general - indicating often widely agreed, though not wholly accepted, views. 
The issue we have focussed upon is that of the IOC's attempts to define the principles of good governance in Olympic sport. Such top-down initiatives, as we have seen, are not entirely uncontested, and their moral and legal basis is subject to challenge. What this paper reports is a policy approach which seeks to engage with the prescriptions/advocacy of the IOC in relation to good governance in Olympic sport, while allowing space for local policy actors to select, amend, and give weighting to, indicators and operational measures of good governance. In effect this is a practical example of glocalisation [32].

The problematic of global-local power relations we have discussed in terms of the limits of Habermas's idealised specification of the conditions of argumentation required to arrive at universal consensus. Our paper provides a practical example, and the implications for policy practice are spelt out. The model adopted for evaluating good governance is designed to be more transparent, its findings to be more easily understood, and the implications of its direct application in the public domain more clearly evident, than a mere top-down approach. Having discussed the model in theory we provide the example of an evaluation of an Iranian National Federation whose performance can be assessed cross-sectionally against other NFs, and/or benchmarked longitudinally against itself employing the approach outlined.

While offering a practical tool for policy, embedded in a philosophical critique of Habermas's approach to ethics and public discourse, the approach described here is itself likely to be subject to critique from a number of directions, perhaps most notably Foucauldian analysis which identifies the ways in which knowledge is suffused with mechanisms of control, largely internalised in terms of governmentality and self regulation [33, 34]. Thus the adoption of 'criteria' of good governance and their interpretation and weighting (by those in positions of influence), is likely to reflect the interests of those in positions of power. Habermas's approach of seeking to establish ethical norms through discourse is a target for Foucauldian analysts [35] who would no doubt aim a similar critique at the Neo-Habermasian position we espouse here of generating general rather than universal consensus through discourse. On the other hand, Habermasian scholars are likely to reject our appeal to empirical ethics since it does not meet the idealised requirements of discourse and argumentation that Habermas advocated. Our response to such criticisms would be that arguments developed about the potential exercise of power in identification or selection of business or sporting ethics represent sources of legitimate critique but such critical analysis of the power relations embedded in, and effected and reflected by, these approaches to progressive policy, does not absolve policy makers from the need to strive for emancipatory policy solutions, while the policy solutions themselves need to reflect an aspiration to emulate conditions of discourse which can deliver policy consensus of a general if not universal nature. 


\section{References}

1. Chatziefstathiou, D. and I.P. Henry, Discourses of Olympism: From the Sorbonne 1894 to London 2012. Discourses of Olympism: from the Sorbonne 1894 to London 2012. 2012. 1305.

2. International Olympic Committee, Olympic Charter. 2013, IOC: Lausanne.

3. Henry, I., Bridging Research Traditions and World Views: Universalisation versus generalisation in the case for gender equity, in Transnational and Comparative Research in Sport: Globalisation, Governance and Sport Policy, I. Henry and Institute of Sport and Leisure Policy, Editors. 2007, Routledge: London.

4. Grohmann, K. IOC bans Indian Olympic Association, elections void. Chicago Tribune, 2012.

5. NDTV, Pakistan and Ecuador threatened with International Olympic Committee ban, in NDTV Sports News. 2013, New Delhi Television: New Delhi.

6. de Silva, C. Comment: Sports without politics - will the miracle happen? Mirror Sports, 2013.

7. Carpenter, K., IOC, national governments and the autonomy of sport: An uneasy relationship, in LawInSport: LawInSport - Expert commentary and analysis on the latest issues and legal developments in the world of sport. 2013, LawlnSport. (p.1)

8. Huntington, S., The Clash of Civilizations. 1996, London: Simon \& Schuster.

9. Dunn, M., The 'Clash of Civilizations' and the 'War on Terror'. 49th Parallel, 2007. 20(Winter 2006-7): p. 1-12.

10. Sardar, Z. and M. Wyn Davies, , American Dream, Global Nightmare 2004, Cambridge: Icon Books.

11. Habermas, J., Moral Consciousness and Communicative Action. 1990, Cambridge, Mass.: MIT Press.

12. Tibi, B., Islam between culture and politics. 2001, Houndmills, Basingstoke, Hampshire ; New York: Palgrave. xvii, $271 \mathrm{p}$.

13. Karam, A.M., Women, Islamisms and the State: contemporary feminisms in Egypt. 1998, Basingstoke: Palgrave.

14. MacAloon, J., Scandal and governance: inside and outside the IOC 2000 Commission. Sport in Society, 2011. 14(3): p. 292-308.

15. International Olympic Committee, Report by the IOC 2000 Commission to the 110th IOC Session. 1999, IOC: Lausanne.

16. Bach, T. Basic Universal Principles of Good Governance. in Unity in Diversity - Respect, Responsibility, Reliability: XIII Olympic Congress. 2009. Copenhagen: IOC.

17. International Olympic Committee, Basic Universal Principles of Good Governance of the Olympic and Sports Movement in Seminar on Autonomy of Olympic and Sport Movement, I.O. Committee, Editor. 2008, International Olympic Committee: Lausanne.

18. Chappelet, J.-L. and M. Mrkonjic, Basic Indicators for Better Governance in International Sport (BIBGIS): An assessment tool $f$ or international sport governing bodies in IDHEAP Working Paper. 2013, IDHEAP- Institut des Hautes Etudes en Administration Publique: Lausanne.

19. Burger, S., A. Goslin, and M. Painter-Morland, Compliance with Best Practice Governance Systems by National Sports Federations in South A frica in Aspects of Sport Governance, W.S. Darlene Kluka, Jr, Guido Schilling, Editor. 2005, Meyer \& Meyer Sport: Oxford. p. 125 - 152.

20. Chaker, A., Good governance in sport: A European Survey. 2004, Strasbourg: Council of Europe.

21. Katwala, S., Democratising Global Sport. 2000, London: The Foreign Policy Centre.

22. McNamee, M. and S. Flemming, The ethics of corporate governance in sport: Theory, method, and operationalization, in Aspects of Sport Governance, W.S. Darlene Kluka, Jr, Guido Schilling, Editor. 2005, Meyer \& Meyer Sport: Oxford. p. 125 - 152.

23. Chappelet, J.L. and B. Kubler-Mabbott, The International Olympic Committee and the Olympic System, the governance of world sport. 2008, London: Routledge. 
24. Zwart, F.d. and G. Gilligan, Sustainable Governance in Sporting Organisations in Social Responsibility and Sustainability in Sports, P.e.a. Rodriguez, Editor. 2009, Universidad de Oviedo: Oviedo. p. 165 - 227.

25. Mowbray, D., The contingent and standard governance framework for national governing bodies, in Handbook of Sport Management, L. Robinson, et al., Editors. 2012, Routledge: London. p. 2641.

26. Taylor, M. and N. O'Sullivan, How Should National Governing Bodies of Sport Be Governed in the UK? An Exploratory Study of Board Structure. Corporate Governance-an International Review, 2009. 17(6): p. 681-693.

27. Henry, I. and P.C. Lee, Governance and Ethics, in The Business of Sport Management, J. Beech and S. Chadwick, Editors. 2004, Pearson: London.

28. Saaty, T., The Analytic Hierarchy Process, McGraw-Hill, New York. 1980, New York: McGrawHill.

29. Alexander, M. Decision-Making using the Analytic Hierarchy Process (AHP) and SAS/IML. 2012 [cited 201422 April ]; Available from: http://analytics.ncsu.edu/sesug/2012/SD-04.pdf.

30. Teknomo, K. Analytic Hierarchy Process (AHP) Tutorial, Available from http://people.revoledu.com/kardi/tutorial/AHP/. 2006 [cited 201422 April].

31. Ishizaka, A. and A. Labib, Analytic Hierarchy Process and Expert Choice: Benefits and Limitations. OR Insight. OR Insight, 2009. 22: p. 201-220.

32. Robertson, R., ed. Glocalization: time-space and homogeneity-heterogeneity. Global modernities, ed. M., et al. 1995, Sage: London. 25-44.

33. Foucault, M., Governmentality, in The Foucault Effect: Studies in Governmentality, G. Burchell, C. Gordon, and P. Miller, Editors. 1991, Harvester Wheatsheaf: Hemel Hempstead. p. 87-104.

34. Foucault, M., et al., Technologies of the self : a seminar with Michel Foucault. 1988, London: Tavistock. 166p.

35. Ashenden, S. and D. Owen, Introduction: Foucault, Habermas and the Politics of Critique, in Foucault contra Habermas: Recasting the Dialogue between Genealogy and Critical Theory, S. Ashenden and D. Owen, Editors. 1999, Sage Publications.: London. 